Home | Archives | About | Login | Submissions | Notify | Contact | Search

\author{
ES Home > Vol. 5, No. $1>$ Art. 14
}

Copyright (C) 2001 by The Resilience Alliance

The following is the established format for referencing this article:

Munasinghe, M. 2001. Exploring the linkages between climate change and sustainable development: A challenge for transdisciplinary research. Conservation Ecology 5(1): 14. [online] URL: http://www.consecol.org/vol5/iss1/ art14/

A version of this article in which text, figures, tables, and appendices are separate files may be found by following this link.

\title{
Perspective
}

\section{Exploring the Linkages between Climate Change and Sustainable Development: A Challenge for Transdisciplinary Research}

\author{
Mohan Munasinghe
}

\section{Munasinghe I nstitute for Development (MI ND)}

- Abstract

- Introduction

- IPCC Guidance Paper on Development, Equity, and Sustainability

- The Internal Debate, Outcome, and Lessons Learned

- Responses to this Article

- Literature Cited

\section{ABSTRACT}

In recent years, both sustainable development and climate change have become well known worldwide, and the work of the Intergovernmental Panel on Climate Change (IPCC) has also focused on the nexus of these two key topics. The IPCC third assessment report confirms that global mean temperatures will rise 1.5- 6 degrees Celsius during the next century. Furthermore, climate change will significantly affect the economic, social, and environmental dimensions of sustainable development, as well as key issues like poverty and equity. Therefore, the IPCC is seeking answers to important questions: how future development patterns will affect climate change; how climate change impacts, adaptation, and mitigation will affect future sustainable development prospects; and how climate change responses might be better integrated into emerging sustainable development strategies.

Some key lessons have emerged from these efforts. The IPCC intellectual community has already proved to be quite cohesive and resilient in the face of determined attacks by powerful and well-financed "anti-climate change" 
lobbies. While addressing sustainable development issues, adaptation and learning within the IPCC have further strengthened the network. First, fresh ideas have been brought in to catalyze change. Transdisciplinary approaches are essential to deal with large-scale, long-term, complex, and interlinked issues like sustainable development and climate change. Second, the disciplinary mix has continued to evolve to meet the challenge. However, crossing disciplinary and cultural boundaries requires sound knowledge of one's own discipline (especially its limitations), open-mindedness, great patience, and sincere effort on all sides. Third, IPCC internal processes have adjusted to facilitate beneficial changes, while limiting harmful dissension. E-mail has proved to be a powerful, but potentially risky tool. How something is said could be as important as what is said, to ensure effective communication. Despite some difficult moments, fair-mindedness and good will have prevailed. The IPCC has been able to accommodate different ways of thinking about the problem, as well as new modes of communication, while reinforcing desirable codes of conduct and behavioral norms.

KEY WORDS: climate change, IPCC, sustainable development, transdisciplinary research.

Published: June 4, 2001

\section{NTRODUCTI ON}

Decision makers worldwide are looking for new solutions to many critical problems, including traditional development issues (e.g., economic stagnation, persistent poverty, hunger, malnutrition, and illness), as well as newer challenges (worsening environmental degradation and accelerating globalization). One key approach that has received growing attention is based on the concept of sustainable development or "development which lasts." Meanwhile, the threat of climate change (CC) has also emerged as an unprecedented global challenge to humanity in recent times. Both topics have become well known worldwide, following the adoption of the United Nations' Agenda 21 and the United Nations Framework Convention on Climate Change (UNFCCC) at the 1992 Earth Summit in Rio de Janeiro, Brazil. During the past decade, the work of the Intergovernmental Panel on Climate Change (IPCC) has also converged on the nexus of these two key topics.

The IPCC was established in 1988, by the World Meteorological Organization (WMO) and the United Nations Environment Program (WMO), to assess scientific information on climate change, as well as its environmental and socioeconomic impacts, and to formulate response strategies. Under the aegis of United Nations, the world's foremost climate experts were engaged in a multiyear process to carry out this task. In 1990, the IPCC's First Assessment Report (FAR) focused mainly on the science of climate change, concluding that continued accumulation of anthropogenic greenhouse gases in the atmosphere would lead to climate change whose rate and magnitude were likely to have important impacts on both socioeconomic and natural systems. The Second Assessment Report (SAR), in 1995, deepened the analysis on ecological impacts and provided rough estimates of future economic damage as well as mitigation measures. This report reaffirmed the findings of the First Assessment Report and further stated that "the balance of evidence suggests a discernible human influence on the global climate." The report also predicted a 1-3.5 degrees Celsius increase in global mean temperature and 15-95 $\mathrm{cm}$ rise in mean sea level by 2100 .

The Third Assessment Report (TAR), due to be released in late 2001, further confirms that climate change is inevitable and estimates that the global mean temperature will increase by 1.5- 6 degrees Celsius. The report examines a crucial new topic, involving the interlinkages between climate change and sustainable development. This article seeks to describe some of the lessons learned from the multidisciplinary interactions involved during the writing of the Third Assessment Report, and shows how the integrative, transdisciplinary approach promoted in Conservation Ecology has contributed to the IPCC process.

\section{PCC GUI DANCE PAPER ON DEVELOPMENT, EQUITY, AND SUSTAI NABI LI TY}


The Third Assessment Report consists of three major parts, dealing with (1) the science of climate change; (2) adaptation; and (3) mitigation. These parts are being prepared by working groups 1, 2, and 3 (WG1, WG2, and WG3), respectively. Adaptation includes both short- and long-term responses to climate change, whereas mitigation refers to methods of reducing greenhouse gas emissions. Over 500 "lead authors" from a large variety of disciplines and many countries are organized into chapter-writing teams. Climate scientists predominate in WG1, natural scientists are in the majority in WG2, and economists and energy experts are more common in WG3. Furthermore, many thousands of other experts will review several drafts of the Third Assessment Report before it is approved by all national governments.

The IPCC Bureau (managing the Third Assessment Report) decided to commission guidance papers on several key issues that cut across the working groups and chapters, to ensure consistent treatment. Within the Bureau, the unenviable task of preparing a guidance paper on climate change and sustainable development was assigned to me. In addition to the complexity of the issues involved, most of the authors had little prior exposure to the sustainable development literature. Furthermore, the paper had to be prepared within a few months, in order to feed into the IPCC process before the writing teams began to draft their chapters. The paper was entitled "Development, equity, and sustainability (DES) in the context of climate change" (Munasinghe 2000). Major advances in the integrated analysis of ecological and social systems made by the Resilience Alliance and Conservation Ecology proved to be very helpful in preparing the draft, especially their transdisciplinary approach and concepts like resilience and panarchy of ecosytems across scales (Holling 1998, Gunderson and Holling 2001). Some key points in the DES paper will be summarized below.

Third Assessment Report authors were urged to respond to the following long-term questions:

1) How will future development patterns and scenarios affect climate change?

2) How will climate change impacts, adaptation, and mitigation affect future sustainable development prospects?

3) How could climate change responses be integrated better into emerging sustainable development strategies?

In this context, development, equity, and sustainability are integral elements of sustainable development. Although no universally accepted practical definition of sustainable development exists as yet, the concept now encompasses three major points of view, economic, social, and environmental, which need to be given balanced treatment in the Third Assessment Report (see Fig. 1). Each viewpoint corresponds to a domain (and system) that has its own distinct driving forces and objectives. The economic domain is geared mainly toward improving human welfare (primarily through increases in the consumption of goods and services). The environmental domain focuses on protecting the integrity and resilience of ecological systems. The social domain emphasizes the enrichment of human relationships and achievement of individual and group aspirations.

Fig. 1. Key elements of sustainable development and interconnections. Source: Munasinghe (1993, 2001). 
- growth

- efficiency

- stability

Economic

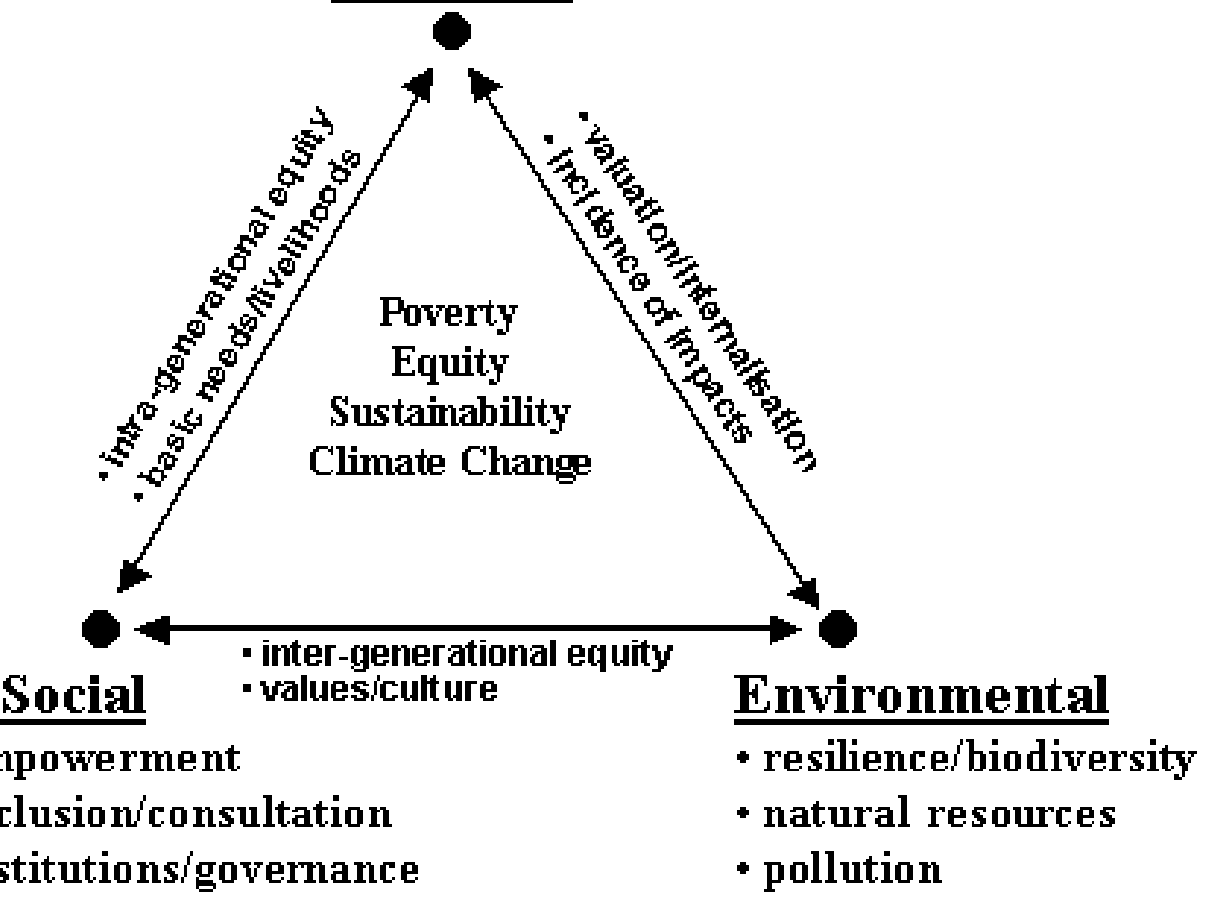

The climate issue is an integral part of the larger question of how circular (and often nonlinear) interactions among the complex panarchy of social, economic, and environmental systems will shape sustainable development prospects over many decades. The capacity to mitigate and adapt to climate change, and the associated mitigation and adaptation costs, depend critically upon the underlying development path, which in turn would be significantly influenced by sustainable development policies and actions. Although there are unavoidable differences among alternative future development paths, no futures are completely free of risk, yet some are less risky than others.

Climate change interactions with sustainable development (including alternative response strategies) could be assessed in a risk management framework, considering long-term effects on: (1) human welfare and equity; (2) the durability and resilience of ecological, geophysical, and socioeconomic systems (especially with respect to sudden, nonlinear system shocks); and (3) the stocks of different kinds of capital (e.g., manufactured, natural, human, and sociocultural assets).

Specific economic, social, and environmental indicators are needed at different levels of aggregation ranging from the global/macro to local/micro. Indicators need to be comprehensive, multidimensional, practical, and must account for regional and scale differences. Because a bewildering array of indicators has already been proposed, Third Assessment Report authors should carefully select those indicators that cut through the complex tangle, and focus on key attributes of sustainable development.

Authors need to engage in a transdisciplinary, integrative process that systematically searches well beyond the mainstream journals, for the small, but growing, volume of literature in economics, ecology, and sociology (and other relevant disciplines) that addresses the nexus of climate change and sustainable development, especially 
research that bridges interdisciplinary gaps.

The different approaches to sustainability must be recognized and reconciled wherever possible. The environmental interpretation focuses on the overall performance or health of ecological systems, defined in terms of a comprehensive, multiscale, dynamic, hierarchical measure of resilience, vigor, and organization. Having greater adaptive capacity is an important advantage, because it increases the range of resilience of such systems and enhances opportunities for development and improvement.

Social sustainability seeks to reduce the vulnerability and maintain the health of social and cultural systems, while enhancing their ability to withstand shocks. Increasing human capital (through education), and strengthening social values and institutions (such as trust and behavioral norms), are key aspects. Adaptive capacity plays a similar role for social systems as for ecosystems. The analogous concept of mitigative capacity is also crucial to ensure that human society becomes more pro-active in abating greenhouse gas emissions that will exacerbate future climate change.

For both ecological and socioeconomic systems across a range of spatial and temporal scales, the emphasis is on improving system health as well as on their dynamic ability to adapt to change and to learn from change, rather than the conservation of some "ideal" static state.

Economic sustainability seeks to maximize the flow of income that could be generated, while at least maintaining the stock of assets (or capital) that yield these benefits. Such stocks of manufactured, natural, human, and social capital not only ensure future production, but also act as a (resilient) bulwark against sudden shocks. Economic efficiency plays a key role in ensuring both efficient allocation of resources in production and efficient consumption choices that maximize utility. The issues of uncertainty, irreversibility, and catastrophic collapse pose additional difficulties in determining dynamically efficient development paths.

Two approaches based on optimality and durability are useful in providing integrated and balanced treatment of the economic, social, and environmental viewpoints. Optimizing economic output is more likely to be the focus (subject to secondary constraints that ensure social and environmental sustainability) when rapid growth is the main objective, uncertainty is a less serious concern, and relevant information is readily available. Alternatively, durable paths that are economically, socially, and environmentally more resilient (but not necessarily growth optimizing) would be the preferred risk-averse option, if sustainability is the primary objective, conditions are uncertain, and data are rather weak.

In this context, sustainable development may be defined as a process for improving the range of opportunities that will enable individual human beings and communities to meet their needs, as well as to achieve their aspirations and full potential, over a sustained period of time. Broadly speaking, development prospects will be enhanced by the search for better productive opportunities, which is driven by the concept of economic efficiency underlying optimization models. Meanwhile, sustainability and resilience are strengthened by durability-based approaches, which focus on increasing adaptive capacity and learning.

The potential of both optimal and durable approaches should be developed to yield consistent and complementary results. Furthermore, it is important to better reconcile the natural science view (which relies more on flows of energy and matter) with the sociological and economic approaches (that focus on human relationships and activities). When the important impacts of a specific climate change option may be valued in economic terms, traditional cost-benefit analysis will provide useful insights. Where certain critical impacts (typically ecological and social) cannot be valued monetarily, other techniques such as multi-criteria analysis would be more effective. High levels of uncertainty and risk need to be dealt with through the use of modern decision analysis frameworks, including risk analysis and risk management.

Poverty and equity (both intra- and intergenerational) are key issues that have not only economic, but also social and environmental dimensions. Therefore, they need to be assessed using a comprehensive set of indicators. Developing countries have the weakest adaptive capacity and will be the most vulnerable to climate change, although they have contributed least to greenhouse gas emissions. I nequitable distributions are not only ethically unappealing, but also are unlikely to be sustainable in the long run because they undermine social cohesion and cooperation, encourage "cheating," and exacerbate conflicts over scarce resources. Even though a climate strategy cannot address all poverty- and equity-related problems, it would be useful to assess whether climate change will worsen existing poverty and inequity. 
Climate change and other global environmental issues such as loss of biodiversity, desertification, and stratospheric ozone depletion are inextricably linked with each other, as well as with more localized environmental problems. Recognition of these key linkages and their close relationship to basic human needs provides policy makers an excellent incentive to address global environmental issues at the local, national, and regional levels. Although much of the work on climate change issues has focused on the global or regional level, climate change impacts and responses will take place mainly at the national and local levels. Therefore, climate change responses need to be harmonized with national sustainable development strategies, including powerful macro-economic policies. This would reduce the potential for conflict between two important current trends: the increased emphasis on freeing markets to promote growth, and protection of the global environment.

One important challenge is to identify "win-win" strategies, which would favor development paths that reduce GHG emissions without undermining prospects for reducing poverty and improving human welfare. Institutional and governance issues would be crucial in implementing adaptation and mitigation measures. Thus, the Third Assessment Report could be more useful to decision makers if it is able to incorporate the viewpoints of all stakeholders, including governments, business, civil society, and nongovernmental organizations.

\section{THE I NTERNAL DEBATE, OUTCOME, AND LESSONS LEARNED}

The first draft of the DES paper was circulated via e-mail to all Third Assessment Report lead authors in late 1999, and a spirited debate ensued, unprecedented in IPCC history. Over 50 individuals participated, including natural scientists, economists, sociologists, geographers, climate scientists, developmental specialists, environmentalists, political scientists, general policy analysts, and others with mixed backgrounds. The discussion evolved through three overlapping phases. It began with a heavily critical e-mail jointly signed by six neoclassical economists, urging that the paper be discarded. They claimed that the role of economics had been diminished, while a new framework was being introduced (linking economic, social, and environmental concepts), which did not reflect consensus opinion.

In the second phase, many others responded individually, (1) broadly agreeing with the main thrust of the paper, (2) offering specific but constructive criticisms, and (3) rebutting the original six critics. There was general support for the need to bridge disciplinary approaches via the holistic, balanced framework combining economic, social, and environmental viewpoints (e.g., Fig.1), and for reconciling optimality/efficiency with durability/resilience. Most agreed that the paper outlined a flexible approach, rather than being a straightjacket to force consensus, because it drew attention to the main issues and suggested options to address them.

Criticism of the paper focused on the lack of specific practical guidance to apply the new framework, requests for more details on economic, ecological, and social indicators to assess the sustainability of alternative futures, and many minor technical corrections to sharpen the accuracy. Some colleagues even felt that the paper was too oriented toward economic efficiency, and should focus more on poverty, equity, and sustainability issues.

The original six critics were also faulted for selectively misrepresenting arguments presented in the paper, exaggerating the role of economics while overlooking its shortcomings, and failing to accept the importance of key sustainable development issues relating to poverty, equity, and sustainability. They were further criticized for "ganging up" early to pre-empt and choke off further discussion, and for adopting a "hegemonistic," confrontational, and harsh tone inappropriate for effective scientific dialogue within the IPCC.

The final phase was marked by much milder exchanges, many involving second thoughts. A deeper dialogue took place among participants, and many points of agreement emerged. The original six critics withdrew their objections and the DES paper was revised and finalized (Munasinghe 2000). Subsequent discussions continued in a collegial and convergent manner, within and across the writing teams of specific chapters of the Third Assessment Report.

Judging the success of this exercise is best left to readers of the Third Assessment Report. My (perhaps biased) view is that the IPCC process was further strengthened. Everyone (especially myself) ended up with a better idea 
of each others' viewpoints, and there was surprisingly little rancor at the end. Minds became more open and the transdisciplinary dialogue improved. Despite differences in academic training, culture, and outlook, an underlying sense of fellowship prevailed: that the unique, and hitherto highly successful, IPCC process was indeed worth protecting. Sustainable development issues were explicitly introduced into the Third Assessment Report and associated documents. However, treatment of sustainable development across chapters remains uneven. Even greater progress could have been made if the early selection process for lead authors had recognized the need for experts with a better grasp of these issues. The sentiment within the IPCC Bureau and the main governing body (the IPCC Plenary) has become even stronger that the next (fourth) assessment report must fully incorporate sustainable development concerns.

Next, I will summarize some key lessons learned from this experience (which were communicated earlier to IPCC colleagues, in my concluding e-mail). It is clear that transdisciplinary work is essential to deal with large-scale, long-term, complex, and interlinked issues like sustainable development and climate change. However, crossing disciplinary and cultural boundaries requires sound knowledge of one's own discipline (especially its limitations), open-mindedness, great patience, and sincere effort on all sides. A heuristic approach is essential to maintain the delicate, dynamic balance between the twin objectives of promoting holistic integration across disciplines and preserving the rigor of individual disciplinary models.

The continuing IPCC process has greater value than any given result, because our knowledge is far from complete and constantly evolving. Thus, building good faith and trust (i.e., social capital) among diverse colleagues and understanding different viewpoints are more important longer term goals than being correct on some specific point.

E-mail proved to be a powerful, but potentially risky, tool for quick, broad-based reviews. It was a necessity, given the international scope of exchanges within severe time and resource constraints. However, face-to-face meetings are far less likely to cause ill-feeling in a multidisciplinary, multicultural debate, in which modes of expression vary widely. Often, the "tone" of e-mail dialogues could be misperceived as abrasive, especially when it is not among close friends and colleagues. In such circumstances, HOW something is said could be as important as WHAT is said, to ensure effective communication. Nevertheless, fair-mindedness and good will finally prevailed, despite some difficult moments.

What insights did the debate provide about the resilience of the IPCC intellectual community? This network has already proved to be quite cohesive in the face of determined attacks by powerful and well-financed "anti-climatechange" lobbies. The strong pressure to include sustainable development concerns within the Third Assessment Report was an external stress of a different kind. Adaptation and learning within the IPCC community took place in several ways. First, fresh ideas were brought in to catalyze change. Second, the disciplinary mix evolved to meet the challenge (and will continue to do so). Third, our internal processes adjusted to facilitate beneficial changes, while limiting harmful dissension. We were able to accommodate different ways of thinking about the problem, as well as new modes of communication (e.g., e-mail), while re-enforcing desirable codes of conduct and behavioral norms.

Readers of Conservation Ecology, especially those already familiar with the IPCC's work, could contribute to this ongoing process in several ways. First, comments on both the substance and process described in this perspective would be welcomed. Munasinghe (2001) contains a more detailed exposition of the material. Second, suggestions for new research on the nexus of climate change and sustainable development would be helpful, in view of significant gaps in the existing literature. Finally, insights and lessons learned from other relevant transdisciplinary initiatives are solicited.

\section{RESPONSES TO THIS ARTI CLE}

Responses to this article are invited. If accepted for publication, your response will be hyperlinked to the article. To submit a comment, follow this link. To read comments already accepted, follow this link. 


\section{LITERATURE CITED}

Gunderson, L., and C. S. Holling. 2001. Panarchy: understanding transformations in human and natural systems. Island Press, New York, New York, USA.

Holling, C. S. 1998. Two cultures of ecology. Conservation Ecology 2(2):4. [online] URL: http://www.consecol. org/vol2/iss2/art4/

Munasinghe, M. 1993. Environmental economics and sustainable development. World Bank, Washington, D.C., USA.

Munasinghe, M. 2000. Development, equity and sustainability in the context of climate change. IPCC Guidance Paper. Intergovernmental Panel on Climate Change, Geneva, Switzwerland.

Munasinghe, M. 2001. The sustainomics trans-disciplinary meta-framework for making development more sustainable: applications to energy issues. International J ournal of Sustainable Development $\mathbf{4}(2)$

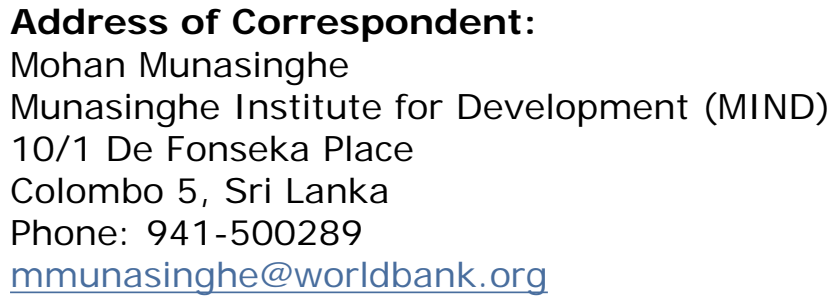

Home | Archives | About | Login | Submissions | Notify | Contact | Search 